\title{
Inhibitory Effects of Dihydrexidine on Catecholamine Release from the Rat Adrenal Medulla
}

\author{
Jae-Hwang LEE ${ }^{1}$, Hyo-Jeong LIM², and Dong-Yoon LIM" ${ }^{3, *}$ \\ ${ }^{1}$ Department of Anesthesiology and Pain Medicine, College of Medicine, Chosun University Hospital, Kwangju 501-759, \\ ${ }^{2}$ Department of Internal Medicine, Seoul National University Hospital, Seoul 110-744, ${ }^{3}$ Department of Pharmacology, \\ Chosun University, Kwangju 501-759, Republic of Korea
}

(Received December 10, 2008; Revised January 16, 2009; Accepted January 17, 2009)

\begin{abstract}
The purpose of the present study was to examine the effect of dihydrexidine, a full $D_{1}$ receptor agonist, on the secretion of catecholamines (CA) from the perfused model of the rat adrenal gland, and to establish its mechanism of action. Dihydrexidine (10-100 $\mu \mathrm{M})$, perfused into an adrenal vein for 60 min, relatively produced dose- and time-dependent inhibition in the CA secretory responses evoked by ACh (5.32 $\mathrm{mM})$, high $\mathrm{K}^{+}(56 \mathrm{mM})$, DMPP $(100 \mu \mathrm{M})$ and McN-A-343 $(100 \mu \mathrm{M})$. Dihydrexidine itself did fail to affect basal CA output. Also, in adrenal glands loaded with dihydrexidine $(30 \mu \mathrm{M})$, the CA secretory responses evoked by Bay-K-8644 $(10 \mu \mathrm{M})$, an activator of L-type $\mathrm{Ca}^{2+}$ channels, cyclopiazonic acid $(10 \mu \mathrm{M})$, an inhibitor of cytoplasmic $\mathrm{Ca}^{2+}$-ATPase, and veratridine, an activator of voltage-dependent $\mathrm{Na}^{+}$channels $(10 \mu \mathrm{M})$, were also markedly inhibited, respectively. However, in the simultaneous presence of dihydrexidine $(30 \mu \mathrm{M})$ and $\mathrm{R}$ (+)-SCH23390 (a selective antagonist of $D_{1}$ receptor, $3 \mu \mathrm{M}$ ), the CA secretory responses evoked by ACh, high $\mathrm{K}^{+}$, DMPP, McN-A-343, Bay-K-8644, cyclopiazonic acid and veratridine were considerably recovered to the extent of the corresponding control secretion compared with the inhibitory responses by dihydrexidinetreatment alone. In conclusion, these experimental results suggest that dihydrexidine significantly inhibits the CA secretion evoked by cholinergic stimulation (both nicotinic and muscarinic receptors) and membrane depolarization from the rat adrenal medulla. It seems that this inhibitory effect of dihydrexidine may be mediated by inhibiting influx of both $\mathrm{Ca}^{2+}$ and $\mathrm{Na}^{+}$into the cytoplasm as well as by suppression of $\mathrm{Ca}^{2+}$ release from cytoplasmic calcium store through activation of dopaminergic $D_{1}$ receptors located on the rat adrenomedullary chromaffin cells.
\end{abstract}

Keywords: Dihydrexidine, Dopamine $D_{1}$ receptors, Adrenal medulla, Catecholamine secretion

\section{INTRODUCTION}

Dihydrexidine, [(+/-)-trans-10,11-dihydroxy-5,6,6a, 7,8,12bhexahydrobenzo[a]phenan-thridine hydrochloride], a full $D_{1}$ receptor agonist, has been available for over 15 years (Lovenberg et al., 1989; Brewster et al., 1990); however, little information is known about the discriminative stimulus effects of this compound despite its clinical development for the treatment of working memory and cognitive deficits

\section{*Corresponding author}

Tel: +82-62-230-6335 Fax: +82-62-227-4693

E-mail: dylim@chosun.ac.kr

This paper was presented at the $18^{\text {th }}$ Scientific Meeting of the International Society of Hypertension held in Berlin, Germany, June 14-19, 2008 in schizophrenia. A previous report demonstrated the ability of dihydrexidine to function as a discriminative stimulus in rats (Schechter, 1995). Gleason and Witkin (2004) found that the $D_{1}$ receptor partial agonist, SKF 38393 , fully substituted and the $\mathrm{D}_{1}$ receptor antagonist $\mathrm{SCH} 23390$ attenuated the discriminative stimulus effects of dihydrexidine. Furthermore, in rats trained to discriminate SKF 38393 from saline, dihydrexidine produced full SKF 38393like responding. Recently, it has been known that the full dopaminergic $D_{1}$ receptor agonist dihydrexidine produces prominent dopamine $D_{1}$ receptor agonist effects in vivo and is likely to produce subjective effects in humans similar to other $D_{1}$ receptor agonists (Gleason and Witkin, 2006). A $D_{1}$-like receptor (the $D_{1}$ receptor class is composed of the $D_{1}$ and $D_{5}$ dopaminergic receptors) has also been identified on bovine chromaffin cells by fluorescence micro- 
scopy (Artalejo et al., 1990). They have also found that stimulation of the $D_{1}$ receptors activates the facilitation of $\mathrm{Ca}^{2+}$ current in the absence of pre-depolarization or repetitive activity, and that activation by $D_{1}$ agonists is mediated by cyclic AMP and protein kinase A. The recruitment of facilitation of $\mathrm{Ca}^{2+}$ channels by dopamine in bovine chromaffin cells may form the basis of a positive feedback loop mechanism for secretion of catecholamines [CA] (Artalejo et al., 1990). More recently, the $D_{1}$ agonist, SKF-38393, enhanced the number of exocytotic events as did prior exposure of the cell to epinephrine from bovine adrenal chromaffin cells (Villanueva and Wightman, 2007). In contrast to these findings, Dahmer and Senogles (1996a) have observed that the $\mathrm{D}_{1}$-selective agonists $\mathrm{Cl}$-APB and SKF38393 inhibit DMPP-stimulated CA secretion in a concentration-dependent manner. Moreover, in bovine adrenal chromaffin cells, $D_{1}$-selective agonists are found to inhibit secretagogue-stimulated $\mathrm{Na}^{+}$uptake in a cyclic AMP-independent manner (Dahmer and Senogles, 1996a).

It has also been demonstrated that apomorphine dosedependently inhibits CA secretion by cholinergic receptor stimulation and also by membrane depolarization from the isolated perfused rat adrenal gland (Lim et al., 1994).

Thus, it is clear that there are still several controversial reports about the role of dopaminergic $D_{1}$-receptors in the $\mathrm{CA}$ release from the adrenal medulla. The purpose of the present study is to examine whether dihydrexidine, a full dopaminergic $D_{1}$ receptor agonist, can modify the CA release from the isolated perfused model of the rat adrenal gland, and to clarify its mechanism of action. This is the first report about the influence of dihydrexidine on the CA secretion form the rat adrenal medulla.

\section{MATERIALS AND METHODS}

\section{Experimental procedure}

Male Sprague-Dawley rats, weighing 200 to 300 grams, were anesthetized with thiopental sodium $(50 \mathrm{mg} / \mathrm{kg})$ intraperitoneally. The adrenal gland was isolated by the methods described previously (Wakade, 1981). The abdomen was opened by a midline incision, and the left adrenal gland and surrounding area were exposed by the placement of three-hook retractors. The stomach, intestine and portion of the liver were not removed, but pushed over to the right side and covered by saline-soaked gauge pads and urine in bladder was removed in order to obtain enough working space for tying blood vessels and cannulations.

A cannula, used for perfusion of the adrenal gland, was inserted into the distal end of the renal vein after all branches of adrenal vein (if any), vena cava and aorta were ligated. Heparin $(400 \mathrm{lU} / \mathrm{ml})$ was injected into vena cava to prevent blood coagulation before ligating vessels and cannulations. A small slit was made into the adrenal cortex just opposite entrance of adrenal vein. Perfusion of the gland was started, making sure that no leakage was present, and the perfusion fluid escaped only from the slit made in adrenal cortex. Then the adrenal gland, along with ligated blood vessels and the cannula, was carefully removed from the animal and placed on a platform of a leucite chamber. The chamber was continuously circulated with water heated at $37 \pm 1^{\circ} \mathrm{C}$.

\section{Perfusion of adrenal gland}

The adrenal glands were perfused by means of peristaltic pump (ISCO ${ }^{\circledR}$ pump, WIZ Co. U.S.A.) at a rate of $0.33 \mathrm{ml} / \mathrm{min}$. The perfusion was carried out with Krebs-bicarbonate solution of following composition (mM): $\mathrm{NaCl}$, 118.4; KCl, 4.7; $\mathrm{CaCl}_{2}, 2.5 ; \mathrm{MgCl}_{2}, 1.18 ; \mathrm{NaHCO}_{3}, 25$; $\mathrm{KH}_{2} \mathrm{PO}_{4}$, 1.2; glucose, 11.7. The solution was constantly bubbled with $95 \% \mathrm{O}_{2}+5 \% \mathrm{CO}_{2}$ and the final $\mathrm{pH}$ of the solution was maintained at 7.4-7.5. The solution contained disodium EDTA $(10 \mu \mathrm{g} / \mathrm{ml})$ and ascorbic acid $(100 \mu \mathrm{g} / \mathrm{ml})$ to prevent oxidation of catecholamines.

\section{Drug administration}

The perfusions of DMPP $\left(10^{-4} \mathrm{M}\right)$ for 2 minutes and/or a single injection of $\mathrm{ACh}\left(5.32 \times 10^{-3} \mathrm{M}\right)$ and $\mathrm{KCl}\left(5.6 \times 10^{-2}\right.$ $M$ ) in a volume of $0.05 \mathrm{ml}$ were made into perfusion stream via a three-way stopcock, respectively. McN-A-343 $\left(10^{-4}\right.$ $\mathrm{M})$, veratridine $\left(10^{-4} \mathrm{M}\right)$, Bay-K-8644 $\left(10^{-5} \mathrm{M}\right)$ and cyclopiazonic acid $\left(10^{-5} \mathrm{M}\right)$ were also perfused for $4 \mathrm{~min}$, respectively.

In the preliminary experiments, it was found that upon administration of the above drugs, the secretory responses to $\mathrm{ACh}, \mathrm{KCl}, \mathrm{McN}-\mathrm{A}-343$, veratridine, Bay-K-8644 and cyclopiazonic acid returned to preinjection level in about 4 $\mathrm{min}$, but the responses to DMPP in $8 \mathrm{~min}$.

\section{Collection of perfusate}

As a rule, prior to stimulation with various secretagogues, the perfusate was collected for 4 min to determine the spontaneous secretion of CA (background sample). Immediately after the collection of the background sample, collection of the perfusates was continued in another tube as soon as the perfusion medium containing the stimulatory agent reached the adrenal gland. Stimulated sample's perfusate was collected for 4 to $8 \mathrm{~min}$. The amounts secreted in the background sample have been subtracted from that secreted from the stimulated sample to obtain the 
net secretion value of $\mathrm{CA}$, which is shown in all of the figures.

To study the effect of dihydrexidine or $\mathrm{R}(+)-\mathrm{SCH} 23390$ on the spontaneous and evoked secretion, the adrenal gland was perfused with Krebs solution containing dihydrexidine or $\mathrm{R}(+)-\mathrm{SCH} 23390$ for $60 \mathrm{~min}$, and then the perfusate was collected for a certain period (background sample). Then the medium was changed to the one containing the stimulating agent or along with dihydrexidine or $\mathrm{R}(+)$ $\mathrm{SCH} 23390$, and the perfusates were collected for the same period as that for the background sample. The adrenal gland's perfusate was collected in chilled tubes.

\section{Measurement of catecholamines}

CA content of perfusate was measured directly by the fluorometric method of Anton and Sayre (1962) without the intermediate purification alumina for the reasons described earlier (Wakade, 1981) using fluorospectrophotometer (Kontron Co., Milano, Italy).

A volume of $0.2 \mathrm{ml}$ of the perfusate was used for the reaction. The CA content in the perfusate of stimulated glands by secretagogues used in the present work was high enough to obtain readings several folds greater than the reading of control samples (unstimulated). The sample blanks were also lowest for perfusates of stimulated and non-stimulated samples. The content of CA in the perfusate was expressed in terms of norepinephrine (base) equivalents.

\section{Statistical analysis}

The statistical difference between the control and pretreated groups was determined by the Student's $t$ and ANOVA tests. A $p$-value of less than 0.05 was considered to represent statistically significant changes unless specifically noted in the text. Values given in the text refer to means and the standard errors of the mean (SEM). The statistical analysis of the experimental results was made by computer program described by Tallarida and Murray (1987).

\section{Drugs and their sources}

The following drugs were used: 6-chloro-7,8-dihydroxy1-phenyl-2,3,4,5-tetrahydro-1H-3-benzazepine (dihydrexidine), $(R)-(+)$-8-chloro-2,3,4,5-tetrahydro-3-methyl-5-phenyl-1H-benzazepine-7-ol [R(+)-SCH23390], cyclopiazonic acid, acetylcholine chloride, 1.1-dimethyl-4-phenyl piperazinium iodide (DMPP), norepinephrine bitartrate, methyl-1,4-dihydro-2,6-dimethyl-3-nitro-4-(2-trifluoro-methylphenyl)-pyridine-5-carboxylate (BAY-K8644), veratridine (Sigma Chemical Co., U.S.A.), and (3-(m-chloro-phenyl- carbamoyl-oxy)-2-butynyltrimethyl ammonium chloride [McNA-343] (RBI, U.S.A.). Drugs were dissolved in distilled water (stock) and added to the normal Krebs solution as required except Bay-K-8644, which was dissolved in 99.5\% ethanol and diluted appropriately with Krebs-bicarbonate solution (final concentration of alcohol was less than $0.1 \%)$. Concentrations of all drugs are expressed in terms of molar base.

\section{RESULTS}

\section{Effects of dihydrexidine on CA secretion evoked by ACh, high $\mathrm{K}^{+}$, DMPP and McN-A-343 from the perfused rat ad- renal glands}

After the perfusion with oxygenated Krebs-bicarbonate solution for $1 \mathrm{hr}$, basal CA release from the isolated perfused rat adrenal glands amounted to $21 \pm 2 \mathrm{ng}$ for $2 \mathrm{~min}$ $(n=9)$. Since in bovine adrenal chromaffin cells, $D_{1}$-selective agonists are found to inhibit secretagogue-stimulated $\mathrm{Na}^{+}$uptake in a cyclic AMP-independent manner (Dahmer and Senogles, 1996a), it was attempted initially to examine the effects of dihydrexidine itself on CA secretion from the perfused model of the rat adrenal glands. However, in the present study, dihydrexidine $\left(10^{-5}-10^{-4} \mathrm{M}\right)$ itself did not produce any effect on basal CA output from perfused rat adrenal glands (data not shown). Therefore, it was decided to investigate the effects of dihydrexidine on cholinergic receptor stimulation- as well as membrane depolarizationmediated CA secretion. Secretagogues were given at 15 min-intervals. Dihydrexidine was present for 60 minutes after the establishment of the control release.

When $\mathrm{ACh}\left(5.32 \times 10^{-3} \mathrm{M}\right)$ in a volume of $0.05 \mathrm{ml}$ was injected into the perfusion stream, the amount of CA secreted was 1,376 $\pm 52 \mathrm{ng}$ for $4 \mathrm{~min}$. However, in the presence of dihydrexidine in the range of $10^{-5}-10^{-4} \mathrm{M}$ for 60 min, ACh-stimulated CA secretion was inhibited in concentration- and time-dependent fashion. As shown in Fig. 1 (Upper), in the presence of dihydrexidine, CA releasing responses were inhibited by $42 \%$ of the corresponding control release. Also, the depolarizing agent, high potassium markedly stimulated the CA secretion ( $649 \pm 32 \mathrm{ng}$ for $0-4$ $\mathrm{min})$. However, following the pretreatment with dihydrexidine $\left(10^{-5} \mathrm{M}-10^{-4} \mathrm{M}\right)$, high $\mathrm{K}+\left(5.6 \times 10^{-2} \mathrm{M}\right)$-stimulated CA secretion was significantly inhibited by $36 \%$ of the control at last period (60-64 min) as shown in Fig. 1 (Lower). $\operatorname{DMPP}\left(10^{-4} \mathrm{M}\right)$, which is a selective nicotinic $\left(\mathrm{N}_{\mathrm{N}}\right)$ receptor agonist in autonomic sympathetic ganglia, evoked a sharp and rapid increase in CA secretion $(1,278 \pm 41 \mathrm{ng}$ for $0-8$ $\mathrm{min})$. However, as shown in Fig. 2 (Upper), DMPP-evoked CA secretion after pretreatment with dihydrexidine was 
greatly reduced to $42 \%$ of the control release $(100 \%)$. McN-A-343 $\left(10^{-4} \mathrm{M}\right)$, which is a selective muscarinic $\mathrm{M}_{1}$-receptor agonist (Hammer and Giachetti, 1982), perfused into an adrenal gland for $4 \mathrm{~min}$ also caused an increased CA secretion (514 $\pm 27 \mathrm{ng}$ for 0-4 $\mathrm{min}$ ). However, in the presence of dihydrexidine, McN-A-343-evoked CA

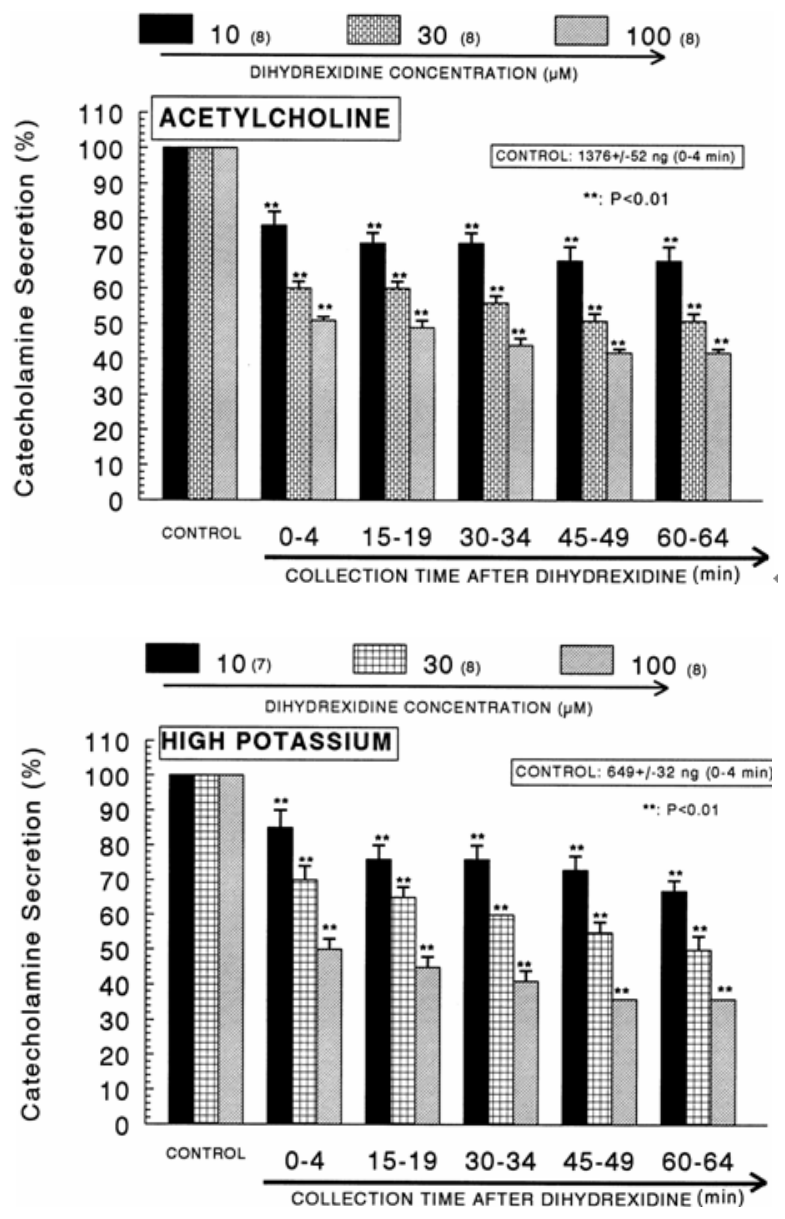

Fig. 1. Dose-dependent effect of dihydrexidine on the secretory responses of catecholamines (CA) evoked by acetylcholine (upper) and high potassium (lower) from the isolated perfused rat adrenal glands. The CA secretion by a single injection of ACh $\left(5.32 \times 10^{-3} \mathrm{M}\right)$ and $\mathrm{K}^{+}\left(5.6 \times 10^{-2} \mathrm{M}\right)$ in a volume of 0.05 $\mathrm{ml}$ was evoked at $15 \mathrm{~min}$ intervals after preloading with 10, 30 and $100 \mu \mathrm{M}$ of dihydrexidine for $90 \mathrm{~min}$ as indicated at an arrow mark, respectively. Numbers in the parenthesis indicate number of rat adrenal glands. Vertical bars on the columns represent the standard error of the mean (S.E.M.). Ordinate: the amounts of CA secreted from the adrenal gland (\% of control). Abscissa: collection time of perfusate (min). Statistical difference was obtained by comparing the corresponding control (CONTROL) with each concentration-pretreated group of dihydrexidine. $\mathrm{ACh}-$ and high $\mathrm{K}^{+}$-induced perfusates were collected for 4 minutes, respectively. ${ }^{* *} p<0.01$. secretion was markedly depressed to $43 \%$ of the corresponding control secretion (100\%) as depicted in Fig. 2 (Lower).

\section{Effect of dihydrexidine on CA secretion evoked by Bay- $\mathrm{K}-8644$, cyclopiazonic acid and veratridine from the per- fused rat adrenal glands}

Since Bay-K-8644 is known to be a calcium channel activator, which enhances basal $\mathrm{Ca}^{2+}$ uptake (Garcia et al., 1984) and CA release (Lim et al., 1992), it was of interest

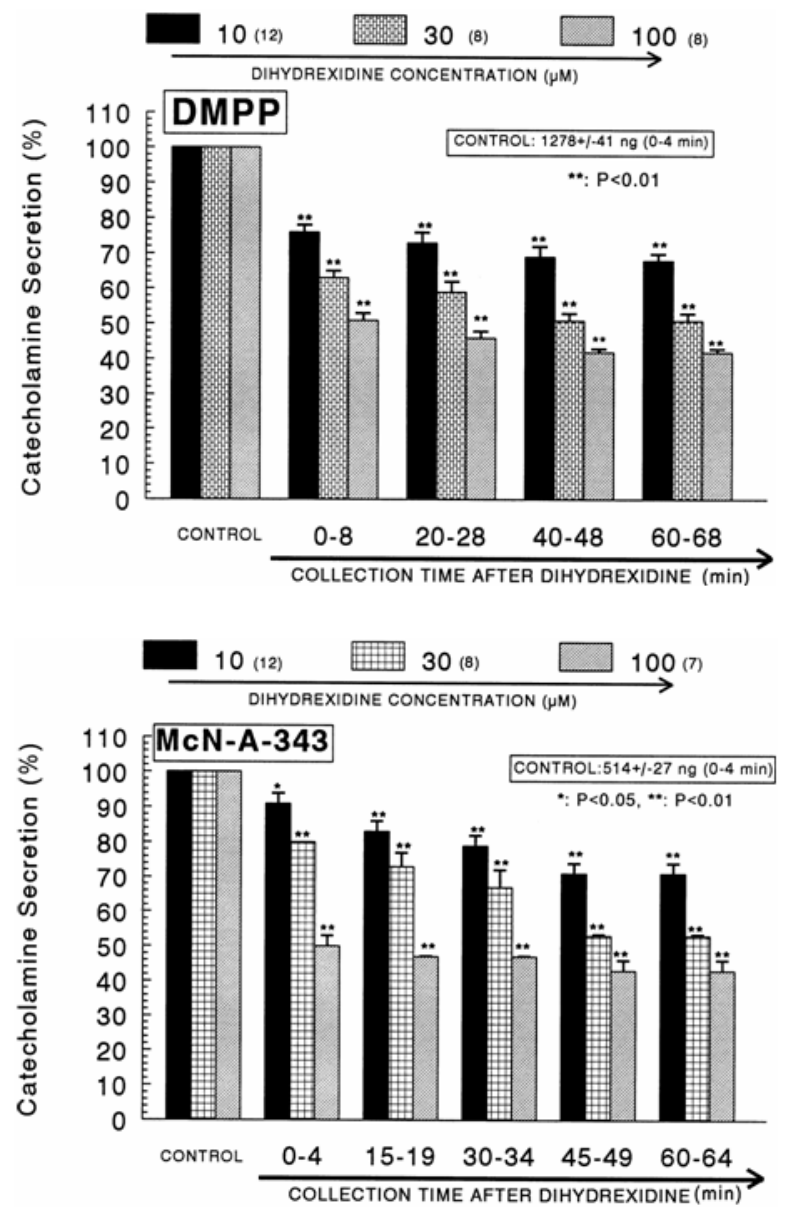

Fig. 2. Dose-dependent effect of dihydrexidine on the CA secretory responses evoked by DMPP (upper) and McN-A-343 (lower) from the isolated perfused rat adrenal glands. The $C A$ secretion by perfusion of DPPP $\left(10^{-4} \mathrm{M}\right)$ and McN-A-343 $\left(10^{-4}\right.$ M) for 2 min was induced at 15 and 20 min intervals after preloading with 10,30 and $100 \mu \mathrm{M}$ of dihydrexidine for $90 \mathrm{~min}$, respectively. Statistical difference was obtained by comparing the corresponding control (CONTROL) with each concentration-pretreated group of dihydrexidine. DMPP- and McN-A343-induced perfusates were collected for 8 and 4 minutes, respectively. Other legends are the same as in Fig. 1. ${ }^{*} p<0.05$, ${ }^{* *} p<0.01$. ns: Statistically not significant. 
to determine the effect of dihydrexidine on Bay-K-8644evoked CA secretion from the isolated perfused rat adrenal glands. Bay-K-8644 (10 $\left.{ }^{-5} \mathrm{M}\right)$-evoked CA secretion in the presence of dihydrexidine $(30 \mu \mathrm{M})$ was greatly blocked to $53 \%$ of the control at $45-64$ min period as compared to the corresponding control release (480 $\pm 21 \mathrm{ng}$ for $0-4 \mathrm{~min})$ from 8 adrenal glands as shown in Fig. 3 (Upper).

Cyclopiazonic acid, a mycotoxin from Aspergillus and Penicillium, has been described as a highly selective inhibitor of $\mathrm{Ca}^{2+}$-ATPase in skeletal muscle sarcoplasmic reticulum (Goeger and Riley, 1989; Seidler et al., 1989). The inhibitory action of dihydrexidine on cyclopiazonic acid-evoked CA secretory response was observed as shown in Fig. 3 (Lower). In the presence of dihydrexidine

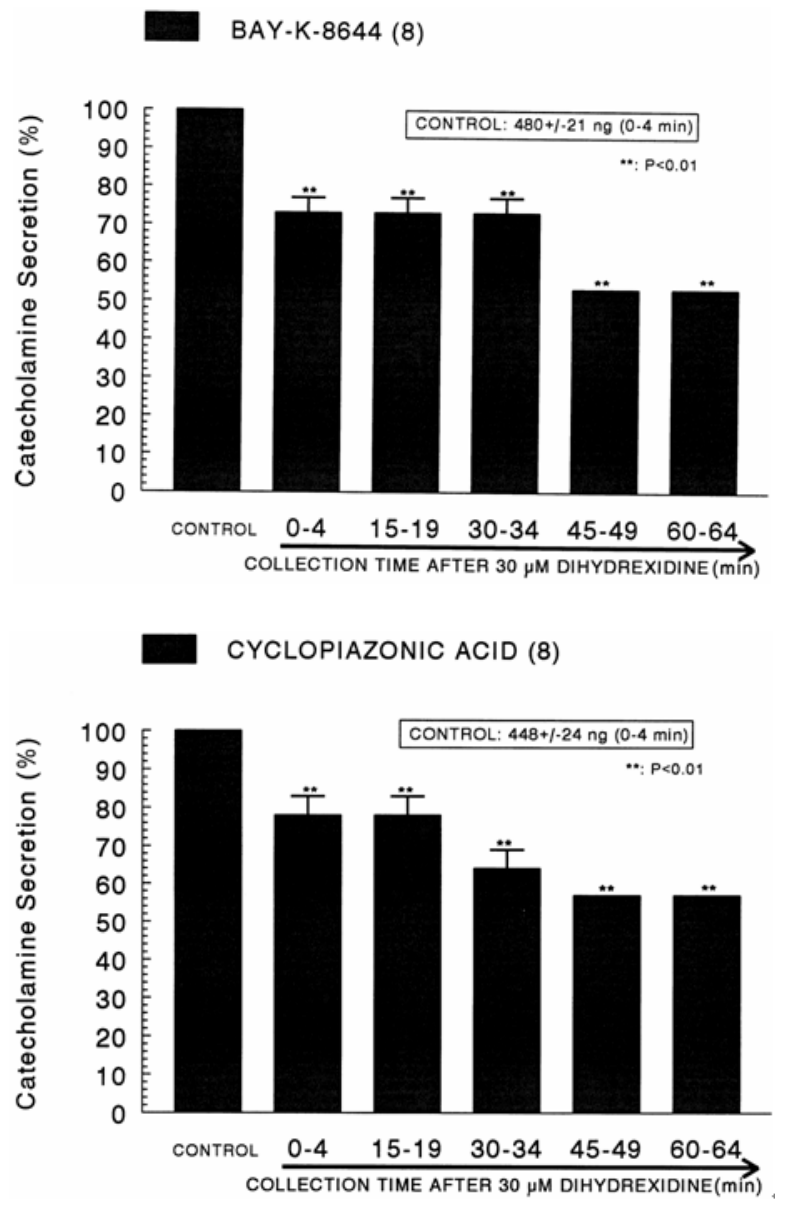

Fig. 3. Time-course effects of dihydrexidine on the CA release evoked by Bay-K-8644 (upper) and cyclopiazonic acid (lower) from the rat adrenal glands. Bay-K-8644 $\left(10^{-5} \mathrm{M}\right)$ and cyclopiazonic acid $\left(10^{-5} \mathrm{M}\right)$ were perfused into an adrenal vein for $4 \mathrm{~min}$ at $15 \mathrm{~min}$ intervals after preloading with dihydrexidine $(30 \mu \mathrm{M})$ for $90 \mathrm{~min}$, respectively. Other legends are the same as in Fig. 1. ${ }^{* *} p<0.01$. from 8 adrenal glands, cyclopiazonic acid $\left(10^{-5} \mathrm{M}\right)$-evoked CA secretion was also inhibited to $57 \%$ of the control response (448 $\pm 24 \mathrm{ng}$ for 0-4 $\mathrm{min}$ ).

The voltage-dependent $\mathrm{Na}^{+}$channels consist of the principal $\alpha$-subunit, which is associated with a noncovalently attached $\beta_{1}$-subunits, and a disulfide-linked $\beta_{2}$-subunit (Catterall, 2000). It has also been known that veratridine-induced $\mathrm{Na}^{+}$influx mediated through $\mathrm{Na}^{+}$channels increased $\mathrm{Ca}^{2+}$ influx via activation of voltage-dependent $\mathrm{Ca}^{2+}$ channels and produced the exocytotic secretion of CA in cultured bovine adrenal medullary cells (Wada et al., 1985). To characterize the pharmacological action of dihydrexidine on voltage-dependent $\mathrm{Na}^{+}$channels, the effect of dihydrexidine on the CA secretion induced by veratridine was examined here. As shown in Fig. 4, veratridine greatly produced CA secretion (1,072 $\pm 48 \mathrm{ng}$ for 0-4 min). However, in the presence of dihydrexidine $(30 \mu \mathrm{M})$, veratridine $(100 \mu \mathrm{M})$-evoked CA secretion was greatly inhibited to $43 \%$ of the corresponding control release.

\section{Effects of dihydrexidine plus $\mathrm{R}(+)-\mathrm{SCH} 23390$ on CA rele- ase evoked by $\mathrm{ACh}$, high $\mathrm{K}^{+}$, DMPP and McN-A-343 from the perfused rat adrenal glands}

As shown in Fig. 1-3, it has also been shown that dihydrexidine inhibits the CA secretory response evoked by cholinergic stimulation in the perfused rat adrenal gland. Therefore, to study the relationship between dopaminergic $D_{1}$ receptors and CA release, the effects of $R(+)$ $\mathrm{SCH} 23390$ on dihydrexidine-induced inhibitory responses

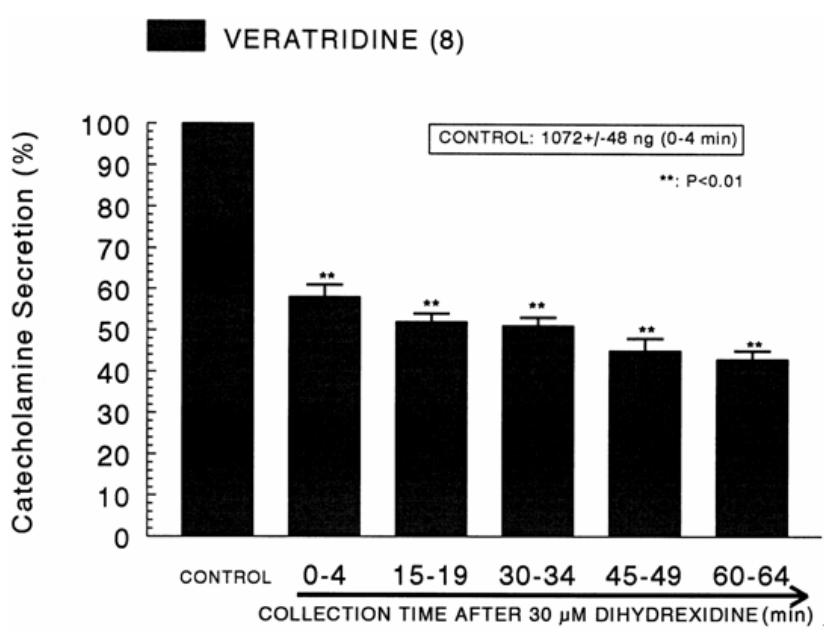

Fig. 4. Time-course effects of dihydrexidine on the CA release evoked by veratridine from the rat adrenal glands. Veratridine $\left(10^{-4} \mathrm{M}\right)$ was perfused into an adrenal vein for $4 \mathrm{~min}$ at $15 \mathrm{~min}$ intervals after preloading with dihydrexidine $(30 \mu \mathrm{M})$ for $90 \mathrm{~min}$. Other legends are the same as in Fig. $1 .{ }^{* *} p<0.01$. 
of CA secretion evoked by cholinergic receptor-stimulation as well as membrane depolarization were examined. In the simultaneous presence of dihydrexidine $(30 \mu \mathrm{M})$ and $\mathrm{R}$ (+)-SCH23390 (3 $\mu \mathrm{M})$ for $60 \mathrm{~min}$, ACh-evoked CA release was recovered by $79-90 \%$ of the corresponding control release compared to results after loading of dihydrexidine alone as illustrated in Fig. 5 (Upper). High $\mathrm{K}^{+}$(56 $\mathrm{mM}$ )-evoked CA release in the simultaneous presence of dihydrexidine $(30 \mu \mathrm{M})$ and $\mathrm{R}(+)-\mathrm{SCH} 23390(3 \mu \mathrm{M})$ for 60 min was also recovered by $76-100 \%$ of the corresponding

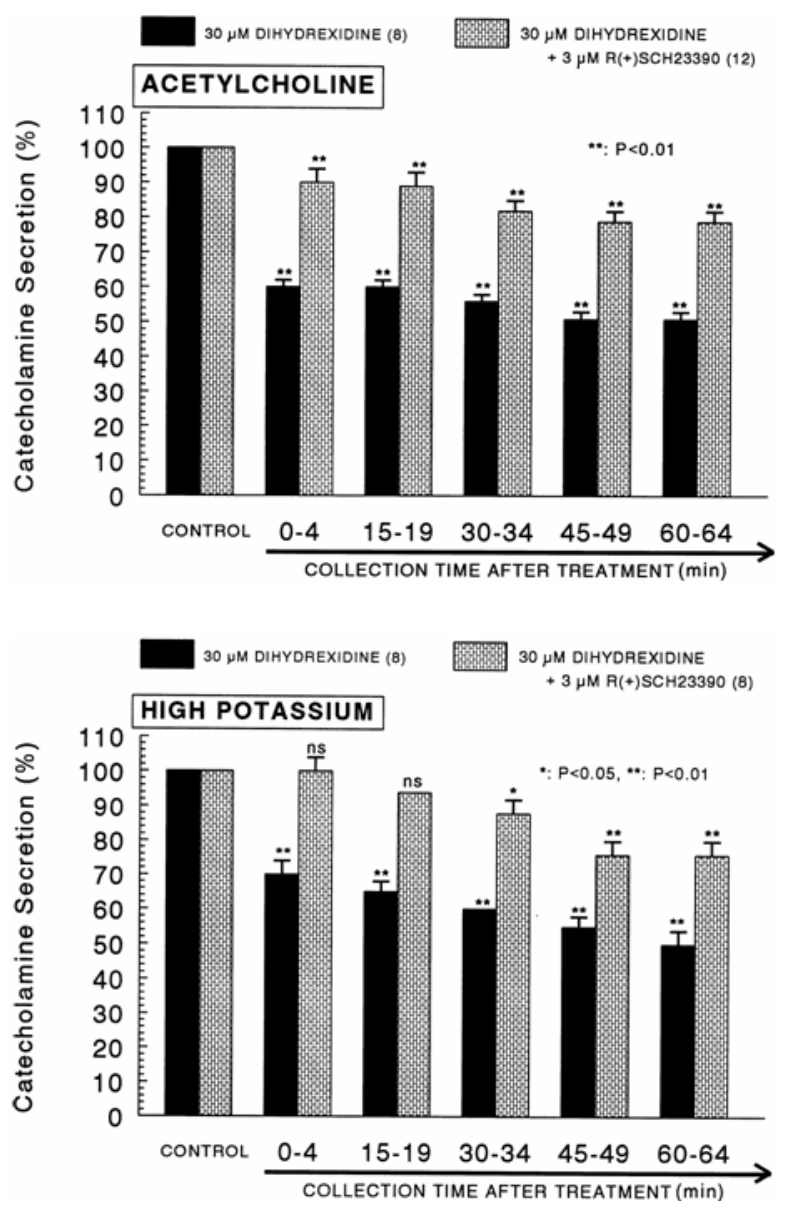

Fig. 5. Effects of dihydrexidine plus $\mathrm{R}(+)-\mathrm{SCH} 23390$ on the CA secretory responses evoked by acetylcholine (upper) and high potassium (lower) from the perfused rat adrenal glands. The CA secretion by a single injection of ACh $\left(5.32 \times 10^{-3} \mathrm{M}\right)$ and $\mathrm{K}^{+}\left(5.6 \times 10^{-2} \mathrm{M}\right)$ in a volume of $0.05 \mathrm{ml}$ was evoked at 15 min intervals after preloading with dihydrexidine $(30 \mu \mathrm{M})$ plus $\mathrm{R}(+)-\mathrm{SCH} 23390(3 \mu \mathrm{M})$ for $90 \mathrm{~min}$, respectively. Statistical difference was obtained by comparing the corresponding control (CONTROL) with dihydrexidine-treated group or group treated with dihydrexidine plus $\mathrm{R}(+)-\mathrm{SCH} 23390$. Other legends are the same as in Fig. $1 .{ }^{*} p<0.05,{ }^{* *} p<0.01$. ns: Statistically not significant. control release during all periods in comparison to data of treatment with dihydrexidine alone (Fig. 5-Lower).

As shown in Fig. 6 (Upper), the simultaneous perfusion of dihydrexidine and $\mathrm{R}(+)-\mathrm{SCH} 23390$ for 60 min got over the DMPP-evoked CA release to $78-90 \%$ of the corresponding control response in comparison to that of the dihydrexidine-treatment alone. Moreover, in the presence of dihydrexidine $(30 \mu \mathrm{M})$ and $\mathrm{R}(+)-\mathrm{SCH} 23390(3 \mu \mathrm{M})$, the CA secretory response evoked by $\mathrm{McN}-\mathrm{A}-343\left(10^{-4} \mathrm{M}\right.$ for $4 \mathrm{~min}$ ) was recovered to $73-100 \%$ of the corresponding control release compared to results of the dihydrexidine-treatment alone, as shown in Fig. 6 (Lower).

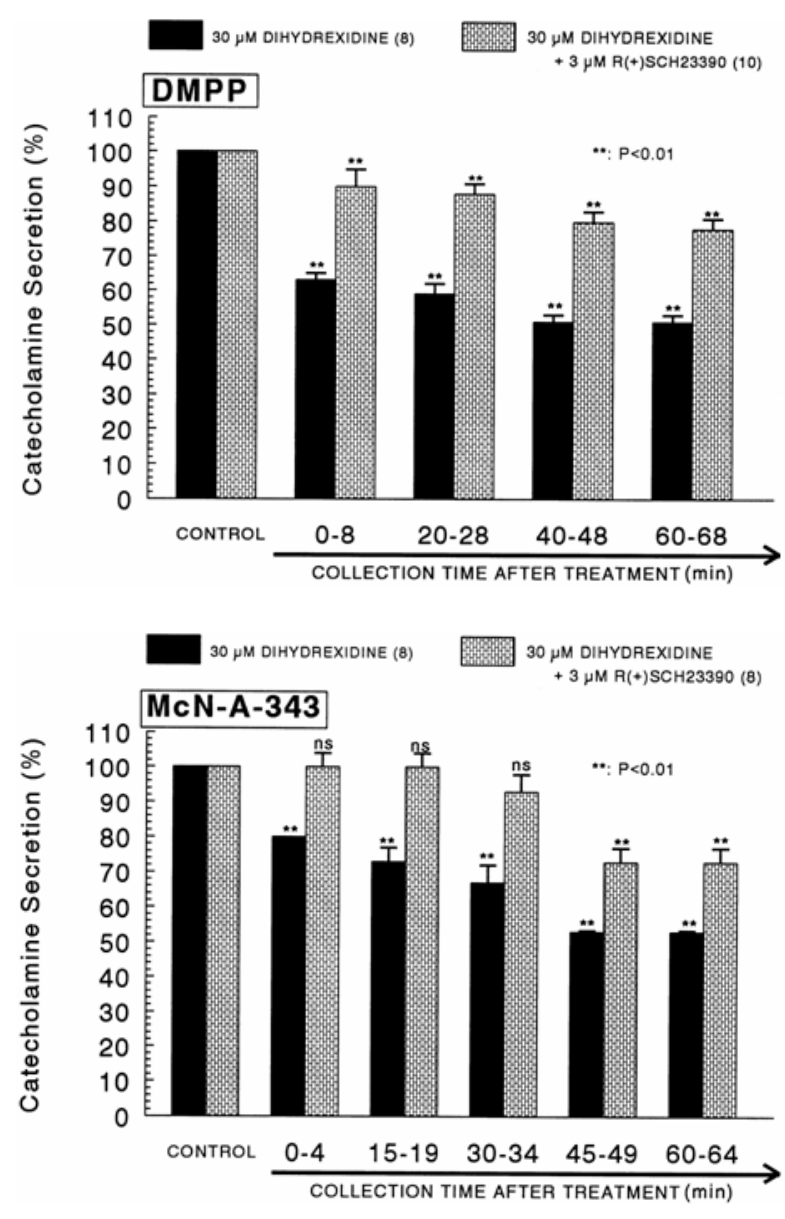

Fig. 6. Effects of dihydrexidine plus $\mathrm{R}(+)-\mathrm{SCH} 23390$ on the $\mathrm{CA}$ secretory responses evoked by DMPP (upper) and McN-A-343 (lower) from the perfused rat adrenal glands. The CA secretion by perfusion of DPPP $\left(10^{-4} \mathrm{M}\right)$ and McN-A-343 $\left(10^{-4} \mathrm{M}\right)$ for 2 min was induced at 15 and 20 min intervals after preloading with dihydrexidine $(30 \mu \mathrm{M})$ plus $\mathrm{R}(+)-\mathrm{SCH} 23390(3 \mu \mathrm{M})$ for $90 \mathrm{~min}$, respectively. Other legends are the same as in Fig. 1 and $5 .{ }^{* *} p$ $<0.01$. ns: Statistically not significant. 

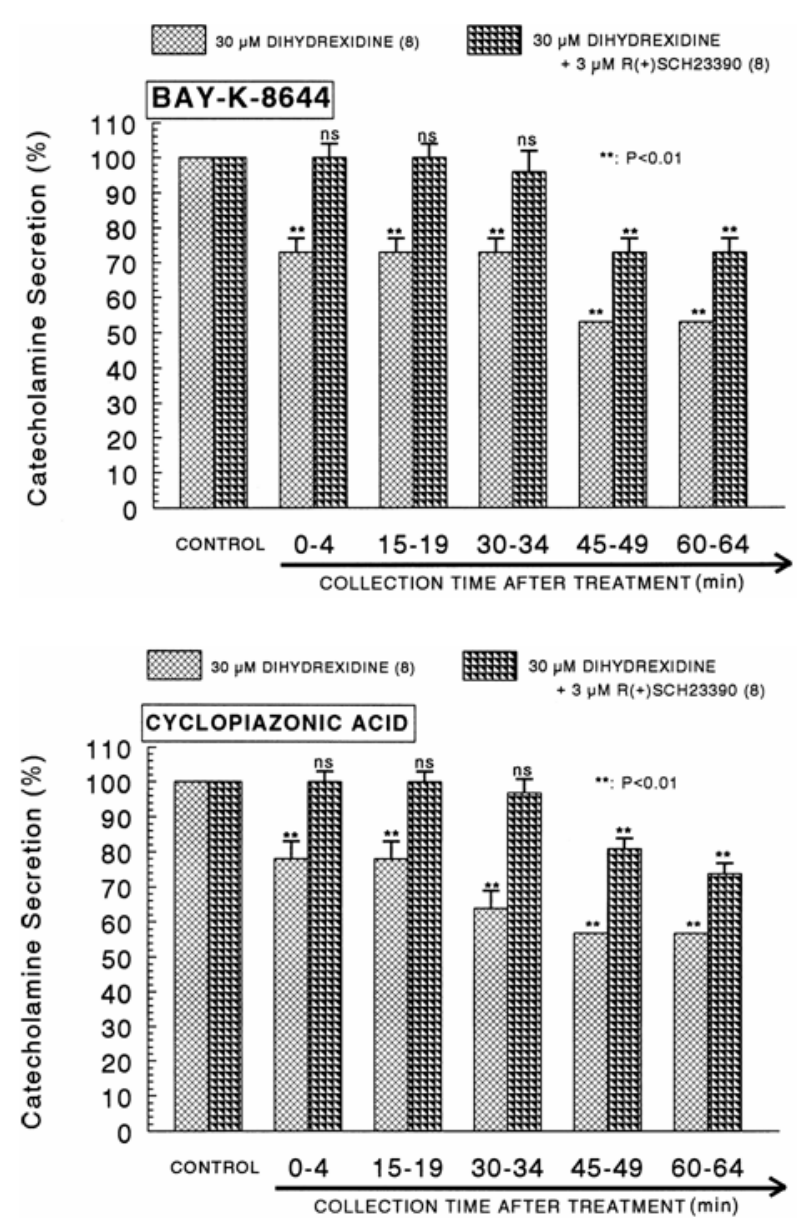

Fig. 7. Effects of dihydrexidine plus $\mathrm{R}(+)-\mathrm{SCH} 23390$ on the CA secretory responses evoked by Bay-K-8644 (upper) and cyclopiazonic acid (lower) from the rat adrenal glands. Bay-K-8644 $\left(10^{-5} \mathrm{M}\right)$ and cyclopiazonic acid $\left(10^{-5} \mathrm{M}\right)$ were perfused into an adrenal vein for $4 \mathrm{~min}$ at $15 \mathrm{~min}$ intervals after preloading with dihydrexidine $(30 \mu \mathrm{M})$ plus $\mathrm{R}(+)-\mathrm{SCH} 23390$ (3 $\mu \mathrm{M})$ for $90 \mathrm{~min}$. Other legends are the same as in Fig. 1 and 5. ${ }^{* *} p<0.01$. ns: Statistically not significant.

\section{Effects of dihydrexidine plus $\mathrm{R}(+)-\mathrm{SCH} 23390$ on CA rele- ase evoked by BAY-K-8644, cyclopiazonic acid and veratridine from the perfused rat adrenal glands}

As shown in Fig. 7 (Upper), the simultaneous perfusion of dihydrexidine $(30 \mu \mathrm{M})$ and $\mathrm{R}(+)-\mathrm{SCH} 23390(3 \mu \mathrm{M})$ for 60 min made the CA release evoked by Bay-K-644 to 73$100 \%$ of the corresponding control response compared to the results of dihydrexidine-treatment alone. After the simultaneous perfusion with dihydrexidine and $\mathrm{R}(+)-\mathrm{SCH}-$ 23390, cyclopiazonic acid-evoked CA release was also recovered by $74-100 \%$ of the control release in comparison to the results following the treatment with dihydrexidine alone (Fig. 7-Lower). As depicted in Fig. 8, in the simultaneous presence of dihydrexidine and $\mathrm{R}(+)-\mathrm{SCH} 23390$,

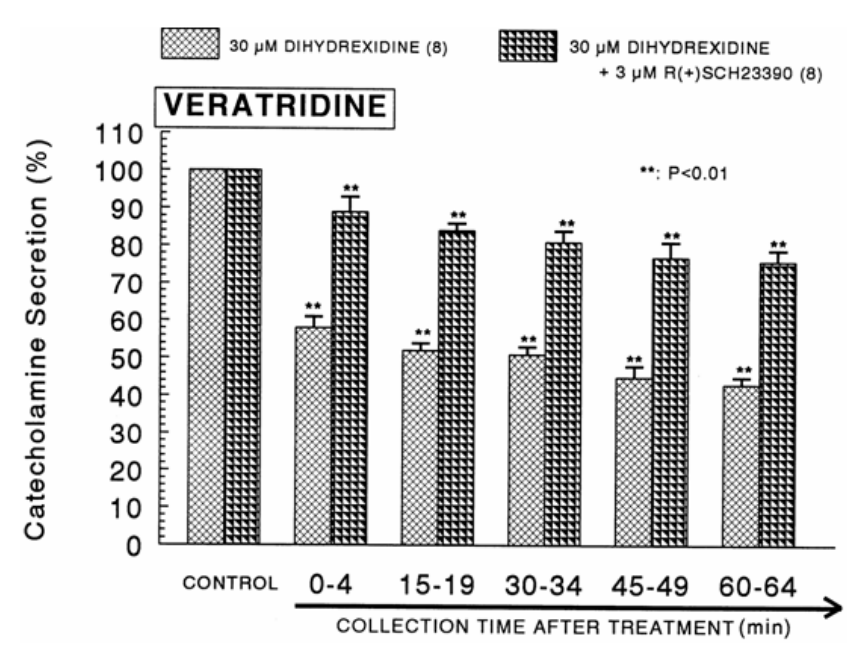

Fig. 8. Effects of dihydrexidine plus $\mathrm{R}(+)-\mathrm{SCH} 23390$ on the $\mathrm{CA}$ secretory responses evoked by veratridine from the rat adrenal glands. Veratridine $\left(10^{-4} \mathrm{M}\right)$ was perfused into an adrenal vein for $4 \mathrm{~min}$ at $15 \mathrm{~min}$ intervals after preloading with dihydrexidine $(30 \mu \mathrm{M})$ plus $\mathrm{R}(+)-\mathrm{SCH} 23390(3 \mu \mathrm{M})$ for $90 \mathrm{~min}$. Other legends are the same as in Fig. 1 and $5 .{ }^{* *} p<0.01$.

veratridine-evoked CA release was also recovered by $76-89 \%$ of the corresponding control release compared to the results of dihydrexidine-treatment alone.

\section{DISCUSSION}

The present study shows that dihydrexidine inhibits the CA secretion evoked by cholinergic stimulation (both nicotinic and muscarinic receptors) and membrane depolarization from the rat adrenal medulla. This inhibitory effect of dihydrexidine seems to be mediated by blocking the influx of $\mathrm{Na}^{+}$and $\mathrm{Ca}^{2+}$ ions through their channels as well as by inhibiting the release of $\mathrm{Ca}^{2+}$ from cytoplasmic store through activation of dopaminergic $D_{1}$ receptors located on the rat adrenomedullary chromaffin cells, which are relevant to adrenal nicotinic receptor blockade.

In support of the present results, previously Artalejo and his co-workers (1990) found specific binding of the rhodamine conjugate of the $\mathrm{D}_{1}$ antagonist $\mathrm{SCH}-23390$ to almost all of the cells in chromaffin cell cultured. Because $\mathrm{SCH}-23390$ will bind $\mathrm{D}_{5}$ receptors as well as $D_{1}$ receptors, it is possible, given the results of RNA analysis by Dahmer and Senogles (1996b), that $D_{5}$-receptors were labeled on the cells. These observations suggested that $D_{5}$ receptors on the cells are responsible for inhibition of secretion by $D_{1}$-selective agonists. Dahmer and Senogles (1996a) have also shown that dopaminergic $D_{1}$-selective agonists inhibit secretagogue-stimulated $\mathrm{Na}^{+}$uptake into bovine adrenal chromaffin cells in a cyclic AMP-independent manner. 
Albillos and his colleagues (1992) have reached two conclusions: First, the cat adrenal medulla chromaffin cell possesses a dopamine $D_{1}$-receptor that seems to be coupled to an adenylyl cyclase. Second, this receptor regulates the muscarinic-mediated CA release through a negative feedback loop which uses cyclic AMP as a second messenger. In addition, $D_{1}$-like receptors have been reported to inhibit secretion (Schoors et al., 1991); however, such a function for members of the $D_{1}$ family of dopamine receptors is controversial.

These previous results are consistent with those obtained from the present study. In the simultaneous presence of $\mathrm{R}(+)-\mathrm{SCH} 23390$ and dihydrexidine, the CA secretory responses evoked by $\mathrm{ACh}$, high $\mathrm{K}^{+}$, and DMPP were recovered to the similar level of their corresponding control responses compared to the inhibitory results of dihydrexidine-treatment alone. This finding confirms that dihydrexidine inhibits the CA secretory responses evoked by cholinergic stimulation as well as membrane depolarization through activation of inhibitory dopaminergic $D_{1}$-receptors on rat adrenal medullary chromaffin cells. Furthermore, electrophysiological studies in awake, behaving monkeys have also shown that iontophoresis of low concentrations of $D_{1}$ antagonists enhances memory-related neuronal firing (Williams and Goldman-Rakic, 1995). Infusions of the selective $D_{1}$ receptor antagonists $\mathrm{R}(+)-\mathrm{SCH} 23390$ or $\mathrm{SCH} 39166$ into the prefrontal cortex of monkeys (Sawaguchi and Goldman-Rakic, 1991) or rats (Seamans et al., 1995) impaired spatial working memory performance, without altering performance of a control task with identical motor and motivational demands but little mnemonic component (Sawaguchi and Goldman-Rakic, 1991). In terms of these findings, it is plausible that dopaminergic $D_{1}$ receptors exist on the rat adrenomedullary chromaffin cells. It has also been reported that, in sinoaortic denervated dogs (i.e. animals deprived from baroreflex pathways), the fenoldopam-induced decrease in arterial blood pressure was more important than in normal dogs (Damase-Michel et al., 1995). Heart rate was unchanged. In these animals, $D_{1}$ stimulation induced a decrease in sympathetic tone, as shown by the significant fall in plasma noradrenaline levels. These "in vivo" data clearly demonstrate the inhibitory role of ganglionic $D_{1}$ receptors. Furthermore, recently, it has also been shown that the full dopaminergic $D_{1}$ receptor agonist dihydrexidine produces prominent dopamine $D_{1}$ receptor agonist effects in vivo and is likely to produce subjective effects in humans similar to other $D_{1}$ receptor agonists (Gleason and Witkin, 2006).

The nicotinic receptor is a neurotransmitter-gated cation-conducting ion channel that is opened by binding of ag- onists such as ACh and DMPP (McGehee and Role, 1995). The opening of this channel triggers $\mathrm{Ca}^{2+}$ uptake and secretion of CA from chromaffin cells (Wada et al., 1985). To determine if the inhibition of DMPP-stimulated secretion by dopaminergic $D_{1}$ agonist was due to an effect on the activity of the nicotinic receptor, the effect of dihydrexidine, a full $\mathrm{D}_{1}$-selective agonist, on DMPP-stimulated CA secretion was examined. As shown in Fig. 2 (Upper), treatment with dihydrexidine greatly inhibited DMPPevoked CA secretion, reducing by $42 \%$ of the control release. The present data are very similar to the result that C1-APB, a $D_{1}$-selective agonist, inhibited DMPP-stimulated $\mathrm{Na}^{+}$uptake in bovine chromaffin cells (Dahmer and Senogles, 1996a). Previous studies have demonstrated that in bovine adrenal chromaffin cells both $D_{1-}$ and $D_{2}$-selective dopamine receptor agonists inhibit CA secretion and $\mathrm{Ca}^{2+}$ uptake stimulated by the nicotinic $\mathrm{ACh}$ receptor agonist DMPP (Dahmer and Senogles, 1996a). Both $D_{1}$ - and $D_{2}$-selective agonists are found to inhibit CA release stimulated by veratridine, an agent that opens voltage-sensitive $\mathrm{Na}^{+}$channels (Dahmer and Senogles, 1996a). It is likely plausible that dihydrexidine can activate a signal transduction pathway that is altering the activity of both nicotinic receptors and voltage-sensitive $\mathrm{Na}^{+}$channels. There have been reports that $\mathrm{D}_{1}$-like dopamine receptors are linked to phosphoinositide metabolism (Felder et al., 1989; Andersen et al., 1990; Undie and Friedman, 1990). Activation of such a pathway could result in elevated levels of $\mathrm{Ca}^{2+}$, diacylglycerol, and inositol trisphosphate in the cells. Consequently, $\mathrm{Ca}^{2+}$-dependent and protein kinase C-dependent pathways may be activated. Protein kinase $C$ has been reported to attenuate the activity of both nicotinic receptors (Swope et al., 1992) and voltage-sensitive $\mathrm{Na}^{+}$channels (Catterall, 1992). It has been proposed that activation of $D_{1}$ receptors on chromaffin cells causes activation of facilitation $\mathrm{Ca}^{2+}$ channels on the cells in a cAMP-dependent manner (Artalejo et al., 1990). However, Dahmer and Senogles (1996b) could find no evidence of message for $D_{1}$ dopamine receptors in chromaffin cells by either PCR analysis or northern blot analysis of RNA. In the present study, dihydrexidine, a $D_{1}$-selective agonist inhibited the CA secretory responses by high potassium as well as by Bay-K-8644, an activator of L-type $\mathrm{Ca}^{2+}$ channels, which facilitates the influx of $\mathrm{Ca}^{2+}$ into the cells. The observation that $D_{1}$-selective agonists inhibited the CA secretion evoked by Bay-K-8644 was surprising, as Artalejo and his colleagues (1990) have reported that $\mathrm{D}_{1}$-selective agonists recruit a facilitation $\mathrm{Ca}^{2+}$ current in bovine chromaffin cells. Although $\mathrm{Ca}^{2+}$ uptake measurements are clearly not the same as measuring $\mathrm{Ca}^{2+}$ 
channel activity, it is difficult to reconcile data indicating that $\mathrm{D}_{1}$-selective agonists can inhibit $\mathrm{Ca}^{2+}$ uptake and facilitate $\mathrm{Ca}^{2+}$ channel activity. Again, one possible explanation is that only a subpopulation of chromaffin cells responds to dopamine agonists by recruiting the facilitation channels.

It is unclear how activation of dopamine receptors results in the inhibition of secretion seen in these cells. The simplest interpretation is that the decrease in $\mathrm{Ca}^{2+}$ uptake by $D_{1}$-selective agonist is responsible for the observed inhibition of the CA secretion. However, such an interpretation is complicated by the complexity of the relationship between the CA secretion and intracellular free $\mathrm{Ca}^{2+}$ levels. Both the intracellular location of the $\mathrm{Ca}^{2+}$ level increase (Cheek, 1989; Ghosh and Greenberg, 1995) and the magnitude of the $\mathrm{Ca}^{2+}$ level increase (Holz et al., 1982) can affect the relationship between intracellular free $\mathrm{Ca}^{2+}$ levels and secretion. Holz and his colleagues (1982) have reported that when $\mathrm{Ca}^{2+}$ uptake is large, changes in $\mathrm{Ca}^{2+}$ uptake resulted in less than proportional changes in $\mathrm{CA}$ secretion. Consequently, although the decrease in $\mathrm{Ca}^{2+}$ uptake (influx) into the adrenal chromaffin cells may explain the decrease by dihydrexidine in CA secretion, it is still unclear whether this is only or even most important factor contributing to the inhibition of CA secretion by dopaminergic $D_{1}$ agonists. However, in view of the results so far obtained from the present study, it is felt that the voltage-sensitive $\mathrm{Ca}^{2+}$ channels located on chromaffin cell membrane of the rat adrenal medulla could be the target site for dihydrexidine-mediated inhibition of CA secretion.

In the present study, dihydrexidine also inhibited the CA secretory responses evoked by cyclopiazonic acid, which is known to be a highly selective inhibitor of $\mathrm{Ca}^{2+}$-ATPase in skeletal muscle sarcoplasmic reticulum (Goeger and Riley, 1989; Seidler et al., 1989). Therefore, it is felt that the inhibitory effect of dihydrexidine on CA secretion evoked by cholinergic stimulation as well as by membrane-depolarization may be associated with the mobilization of intracellular $\mathrm{Ca}^{2+}$ in the chromaffin cells. This indicates that the activation of dopaminergic $D_{1}$-receptors has an inhibitory effect on the release of $\mathrm{Ca}^{2+}$ from the intracellular pools induced by stimulation of muscarinic ACh receptors, which is weakly responsible for the secretion of CA. In the present work, dihydrexidine time- and concentration-dependently produced the inhibition of CA secretion evoked by McN-A-343, a selective muscarinic $\mathrm{M}_{1-}$ agonist. This fact suggests new other concept that dihydrexidine can modulate the CA secretory process induced by activation of muscarinic $\mathrm{M}_{1}$-receptors as well as neuronal nicotinic receptors in the rat adrenal medulla. In sup- porting this finding, it has been shown that cyclopiazonic acid easily penetrates into the cytoplasm through the plasma membrane and reduces $\mathrm{Ca}^{2+}$-ATPase activity in sarcoplasmic/endoplasmic reticulum, resulting in increase in the subsequent $\mathrm{Ca}^{2+}$ release from those storage sites and thereby increases of $\mathrm{Ca}^{2+}$-dependent $\mathrm{K}^{+}$-current (Suzuki et al., 1992). Moreover, in bovine adrenal chromaffin cells, stimulation of muscarinic ACh receptors is also proposed to cause activation of phosphoinositide metabolism, resulting in the formation of inositol 1,4,5-trisphosphate, which induces the mobilization of $\mathrm{Ca}^{2+}$ from the intracellular pools (Cheek et al., 1989; Challiss et al., 1991). However, in the present study, it is uncertain whether the inhibitory effect of the dihydrexidine on $\mathrm{Ca}^{2+}$ movement from intracellular pools is due to their direct effect on the PI response or the indirect effect as a result of $D_{1}$-receptor activation by dihydrexidine. Based on these previous results, this finding of the present work suggests that the inhibitory dopaminergic $D_{1}$-receptors may be involved in regulating $C A$ secretion evoked by muscarinic $\mathrm{M}_{1}$-receptor stimulation in the rat adrenal medullary chromaffin cells.

In contrast with the present experimental results, it has also been shown that stimulation of dopaminergic $D_{1}$-receptors activates the facilitation of $\mathrm{Ca}^{2+}$ currents in the absence of pre-depolarizations or repetitive activity from bovine chromaffin cells, and that activation by $D_{1}$ agonists is mediated by CAMP and protein kinase A (Artalejo et al., 1990). This recruitment of facilitation of $\mathrm{Ca}^{2+}$ channels by dopamine may form the basis of a positive feedback loop mechanism that augments CA secretion.

Taken together, these present results suggest that dihydrexidine inhibits the CA secretion evoked by cholinergic (both nicotinic and muscarinic) receptor stimulation and membrane depolarization from the rat adrenal medulla. It seems that this inhibitory of dihydrexidine is due to activation of dopaminergic $D_{1}$ receptors located on the rat adrenomedullary chromaffin cells, which are relevant to the blockade of influx of both $\mathrm{Na}^{+}$and $\mathrm{Ca}^{2+}$ ions into chromaffin cells as well as to the inhibition of $\mathrm{Ca}^{2+}$ release from the cytoplasmic store.

\section{REFERENCES}

Albillos, A., Abad, F. and Garcia, A. G. (1992). Cross-talk between $M_{2}$ muscarinic and $D_{1}$ dopamine receptors in the cat adrenal medulla. Biochem. Biophys. Res. Commun. 183, 1019-1024.

Andersen, P. H. and Jansen, J. A. (1990). Dopamine receptor agonists: Selectivity and $D_{1}$ receptor efficacy. Eur. J. Pharmacol. 188, 335-347.

Anton, A. H. and Sayre, D. F. (1962). A study of the factors affec- 
ting the aluminum oxidetrihydroxy indole procedure for the analysis of catecholamines. J. Pharmacol. Exp. Ther. 138, 360-375

Artalejo, A. R., Ariano, M. A., Perlman, R. L. and Fox, A. P. (1990). Activation of facilitation calcium channels in chromaffin cells by $D_{1}$ dopamine receptors through a AMP/protein Kinase A-dependent mechanism. Nature 348, 239-242.

Brewster, W. K., Nichols, D. E., Riggs, R. M., Mottola, D. M., Lovenberg, T. W., Lewis, M. H. and Mailman, R. B. (1990). Trans-10,11-dihydroxy-5,6,6a,7,8,12b-hexahydrobeno[a]phenanthridine: a highly potent selective dopamine $D_{1}$ ful agonist. J. Med. Chem. 33, 1756-1764.

Catterall, W. A. (1992). Cellular and molecular biology of voltage-gated sodium channels. Physiol. Rev. 72(4 Suppl), S15-48.

Catterall, W. A. (2000). From ionic currents to molecular mechanisms: the structure and function of voltage-gated sodium channels. Neuron 26, 13-25.

Challiss, R. A., Jones, J. A., Owen, P. J. and Boarder, M. R. (1991). Changes in inositol 1,4,5-trisphosphate and inosito 1,3,4,5-tetrakisphosphate mass accumulations in cultured adrenal chromaffin cells in response to bradykinin and histamine. J. Neurochem. 56, 1083-1086.

Cheek, T. R., O'Sullivan, A. J., Moreton, R. B., Berridge, M. J. and Burgoyne, R. D. (1989). Spatial localization of the stimulus-induced rise in cyrosolic $\mathrm{Ca}^{2+}$ in bovine adrenal chromaffin cells: Distinct nicotinic and muscarinic patterns. FEBS. Lett. 247, 429-434.

Dahmer, M. K. and Senogles, S. E. (1996a). Differential inhibition of secretagogue-stimulated sodium uptake in adrenal chromaffin cells by activation of $D_{4}$ and $D_{5}$ dopamine receptors. J. Neurochem. 67, 1960-1964.

Dahmer, M. K. and Senogles, S. E. (1996b). Doparminergic inhibition of catecholamine secretion from chromaffin cells: Evidence that inhibition is mediated by $D_{4}$ and $D_{5}$ dopamine receptors. J. Neurochem. 66, 222-232.

Damase-Michel, C., Montastruc, J. L. and Tran, M. A. (1995). Effects of dopaminergic drugs on the sympathoadrenal system. Hypertens. Res. 18(Suppl 1), S119-124.

Felder, C. C., Blecher, M. and Jose, P. A. (1989). Dopamine-1 mediated stimulation of phospholipase $C$ activity in rat renal cortical membranes. J. Biol. Chem. 264, 8739-8745.

Garcia, A. G., Sala, F., Reig, J. A., Viniegra, S., Frias, J., Fonteriz, R. and Gandia, L. (1984). Ihydropyridine Bay-K8644 activates chromaffin cell calcium channels. Nature 309, 69-71.

Ghosh, A. and Greenberg, M. E. (1995). Calcium signaling in neurons: molecular mechanisms and cellular consequences. Science. 268, 239-247.

Gleason, S. D. and Witkin, J. M. (2006). Effects of dopamine $D_{1}$ receptor agonists in rats trained to discriminate dihydrexidine. Psychopharmacology (Berl) 186, 25-31.

Gleason, S. D. and Witkin, J. M. (2004). Effects of dopamine $D_{1}$ receptor full agonists in rats trained to discriminate SKF 38393. Behav. Pharmacol. 15, 85-89.

Goeger, D. E. and Riley, R. T. (1989). Interaction of cyclopiazonic acid with rat skeletal muscle sarcoplasmic reticulum vesicles. Effect on $\mathrm{Ca}^{2+}$ binding and $\mathrm{Ca}^{2+}$ permeability. Biochem. Pharmacol. 38, 3995-4003.
Hammer, R. and Giachetti, A. (1982). Muscarinic receptor subtypes: $M_{1}$ and $M_{2}$ biochemical and functional characterization. Life Sci. 31, 2992-2998.

Holz, R. W., Senter, R. A. and Frye, R. A. (1982). Relationship between $\mathrm{Ca}^{2+}$ uptake and catecholamine secretion in primary dissociated cultures of adrenal modulla. $J$. Neurochem. 39, 635-640.

Lim, D. Y., Kim, C. D. and Ahn, K. W. (1992). Influence of TMB-8 on secretion of catecholamines from the perfused rat adrenal glands. Arch. Pharm. Res. 15, 115-125.

Lim, D. Y., Yoon, J. K. and Moon, B. (1994). Interrelationship between dopaminergic receptors and catecholamine secretion from the rat adrenal gland. Korean J. Pharmacol. 30, $87-100$.

Lovenberg, T. W., Brewster, W. K., Mottola, D. M., Lee, R. C., Riggs, R. M., Nichols, D. E., Lewis, M. H. and Mailman, R. B. (1989). Dihydrexidine, a novel selective high potency full dopamine D-1 receptor agonist. Eur. J. Pharmacol. 166, 111113.

McGehee, D. S. and Role, L. W. (1995). Physiological diversity of nicotinic acetylcholine receptors expressed by vertebrate neurons. Annu. Rev. Physiol. 57, 521-546.

Sawaguchi, T. and Goldman-Rakic, P. S. (1991). D dopamine receptors in prefrontal cortex: Involvement in working memory. Science. 251, 947-950.

Schechter, M. D. (1995). The discriminative properties of the $D_{1}$ dopamine agonist dihydrexidine in the rat. Psychopharmacology. 119, 79-84.

Schoors, D. F., Vauquelin, G. P., De Vos, H., Smets, G., Velkeniers, B., Vanhaelst, L. and Dupont, A. G. (1991). Identification of a $D_{1}$ dopamine receptor, not linked to adenylate cyclase, on lactotroph cells. Br. J. Pharmacol. 103, 1928-1934.

Seamans, J. K., Floresco, S. B. and Phillips, A. G. (1995) Selective impairment on a delayed radial arm task following local administration of a $D_{1}$, but not a $D_{2}$, antagonist into the prefrontal cortex. Soc. Neurosci. Abstr. 21, 1942.

Seidler, N. W., Jona, I., Vegh, N. and Martonosi, A. (1989). Cyclopiazonic acid is a specific inhibitor of the $\mathrm{Ca}^{2+}$-ATPase of sarcoplasimc reticulum. J. Biol. Chem. 264, 17816-17823.

Suzuki, M., Muraki, K., Imaizumi, Y. and Watanabe, M. (1992). Cyclopiazonic acid, an inhibitor of the sarcoplasmic reticulum $\mathrm{Ca}^{2+}$-pump, reduces $\mathrm{Ca}^{2+}$-dependent $\mathrm{K}^{+}$currents in guinea-pig smooth muscle cells. Br. J. Pharmacol. 107, 134-140.

Swope, S. L., Moss, S. J., Blackstone, C. D. and Huganir, R. L. (1992). Phosphorylation of ligand-gated ion channels: a possible mode of synaptic plasticity. FASEB J. 6, 2514-2523.

Tallarida, R. J. and Murray, R. B. (1987). Manual of pharmacologic calculation with computer programs. 2nd ed. pp. 132. Speringer-Verlag, New York.

Undie, A. S. and Friedman, E. (1990). Stimulation of a dopamine $D_{1}$ receptor enhances inositol phosphates formation in rat brain. J. Pharmacol. Exp. Ther. 253, 987992.

Villanueva, M. and Wightman, R. M. (2007). Facilitation of quantal release induced by a $D_{1}$-like receptor on bovine chromaffin cells. Biochemistry 46, 3881-3887.

Wada, A., Takara, H., Izumi, F., Kobayashi, H. and Yanagihara, N. (1985). Influx of ${ }^{22} \mathrm{Na}$ through acetylcholine receptor- 
associated $\mathrm{Na}$ channels: relationship between ${ }^{22} \mathrm{Na}$ influx, ${ }^{45} \mathrm{Ca}$ influx and secretion of catecholamines in cultured bovine adrenal medulla cells. Neuroscience 15, 283-292.

Wakade, A. R. (1981). Studies on secretion of catecholamines evoked by acetylcholine or transmural stimulation of the rat adrenal gland. J. Physiol. 313, 463-480.

Williams, G. V. and Goldman-Rakic, P. S. (1995). Blockade of dopamine $D_{1}$ receptors enhances memory fields of prefrontal neurons in primate cerebral cortex. Nature 376, 572-575. 